\title{
ESTUDO DO COMPORTAMENTO DA ULTRAFILTRAÇÃO DE MISTURAS CONTENDO GLICERINA
}

\author{
A. C. D. ALBUQUERQUE ${ }^{1}$, J. F. MEDEIROS ${ }^{1}$, N. C. PEREIRA ${ }^{1}$, M. F. VIEIRA ${ }^{1}$ \\ ${ }^{1}$ Universidade Estadual de Maringá, Departamento de Engenharia Química \\ E-mail para contato: anacdalbuquerque @gmail.com
}

\begin{abstract}
RESUMO - A intensa busca por fontes de energias renováveis e processos sustentáveis visando à redução da poluição ambiental e o aquecimento global, tem estimulado o mercado mundial de biocombustíveis. O biodiesel tem grande destaque na matriz energética nacional e sua produção em larga escala gera grande quantidade de glicerina. A glicerina possui muitas aplicações industriais quando está purificada. A purificação por meio de membranas apresenta muitas vantagens, principalmente devido à redução da geração de efluentes. Com a utilização de misturas contendo glicerina, é possível estudar o comportamento da ultrafiltração, visto que as consequências no uso de etanol e biodiesel, por exemplo, são diferentes. Neste trabalho foram produzidas e analisadas duas misturas contendo quantidades distintas de glicerina, etanol, biodiesel e água acidificada. Constatou-se que fluxo na ultrafiltração é maior para maiores quantidade de biodiesel na mistura, porém ocorre maior fouling na membrana.
\end{abstract}

\section{INTRODUÇÃO}

A partir do recente interesse no desenvolvimento de energias renováveis, o biodiesel tem atraído inúmeros pesquisadores em todo mundo, como uma alternativa viável para diminuir o consumo de combustíveis fósseis. Este grande interesse atribuído ao biodiesel se deve ao fato de ser um combustível de fonte renovável, biodegradável e com baixos níveis de emissão de gases poluentes (Gomes, 2012).

O aumento da produção do biocombustível implica geração de excesso da glicerina no mercado, contribuindo para custos menores de comercialização (Quispe, et al., 2013). Segundo Tan et al. (2013) para a produção de $10 \mathrm{~kg}$ de biodiesel por meio do processo de transesterificação se produz aproximadamente $1 \mathrm{~kg}$ de glicerina bruta. Além disso, segundo Quispe et al. (2013) a glicerina bruta produzida contém grandes quantidades de contaminantes, o que diminui sua qualidade. Portanto, várias pesquisas foram desenvolvidas buscando alternativas de purificação, visando aumentar ainda mais a viabilidade econômica dos biocombustíveis. (Hunson e Autthanit, 2013).

O estudo de Mota et al. (2009) afirma que o glicerol possui a denominação de glicerina quando este produto comercial contém menos de $95 \%$ de glicerol.

De acordo com Ardi et al. (2015) existem várias técnicas de purificação da glicerina, por exemplo, destilação a vácuo, adsorção por troca iônica, adsorção utilizando carvão 
ativado, tecnologia de separação por membranas, entre outras. No processo de separação por membranas é imprescindível a existência de uma forca motriz, que pode ser um gradiente de pressão ou de concentração. Em processos que utilizam membranas porosas, tais como a microfiltração (MF), ultrafiltração (UF) e nanofiltração (NF), a forca motriz é o gradiente de pressão através da membrana (Habert et al., 2006).

As misturas contendo glicerina são constituídas de vários compostos, possivelmente encontrados na indústria de biodiesel. Essas misturas são geralmente produzidas para simular a glicerina bruta que é um subproduto da reação de transesterificação. Simulando as misturas, é possível promover sua purificação, relacionando a glicerina que é produzida industrialmente com as misturas desenvolvidas em laboratório.

Neste trabalho objetiva-se analisar o processo de ultrafiltração de misturas produzidas em laboratório, utilizando membranas cerâmicas, buscando conhecer o comportamento de cada componente após a purificação.

\section{METODOLOGIA}

\subsection{Materiais}

A glicerina bruta utilizada neste trabalho foi doada pela empresa produtora de biodiesel BSBIOS (Marialva, Paraná). O biodiesel foi produzido em laboratório utilizando óleo de soja proveniente da empresa Cocamar (Maringá, Paraná), o etanol foi proveniente da Destilaria Melhoramentos (Jussara, Paraná), e o hidróxido de sódio em pérolas P.A. da marca F. Maia Indústria e Comércio. A água foi acidificada com ácido fosfórico 85\% P.A. da marca F. Maia Indústria e Comércio.

\subsection{Métodos}

Produção do biodiesel: O biodiesel foi produzido pela reação de transesterificação, seguindo os resultados obtidos do planejamento experimental de produção de biodiesel conforme apresentado por Gomes et al., (2011).

Purificação do biodiesel: O biodiesel produzido em laboratório foi submetido à lavagem úmida, seguindo os resultados obtidos nos experimentos de purificação de biodiesel apresentado por Geris et al., (2007).

Purificação da glicerina por ultrafiltração: Foram empregadas membranas cerâmicas, de $\alpha-\mathrm{Al}_{2} \mathrm{O}_{3} / \mathrm{TiO}_{2}$ (Shumacher GmbH-Ti 01070) adquiridas da NETZSCH, do tipo tubular de fluxo tangencial, com comprimento de $250 \mathrm{~mm}$, diâmetro de $7 \mathrm{~mm}$ e área de filtração de $0,005 \mathrm{~m}^{2}$, com diâmetro médio de poros de $5 \mathrm{kDa}$. Os experimentos foram realizados na unidade piloto de ultra/microfiltração UF NETZSCH modelo 027.06-1C1/07-0005/AI, instalada no Laboratório de Processos de Separação II no Departamento de Engenharia Química, como apresentado na Figura 1. 


\section{Congresso Brasileiro de Engenharia Química em Iniciação Científica UFSCar - São Carlos - SP 16 a 19 de Julho de 2017}

Figura 1. Desenho esquemático da unidade piloto de micro e ultrafiltração, (GOMES, 2012)

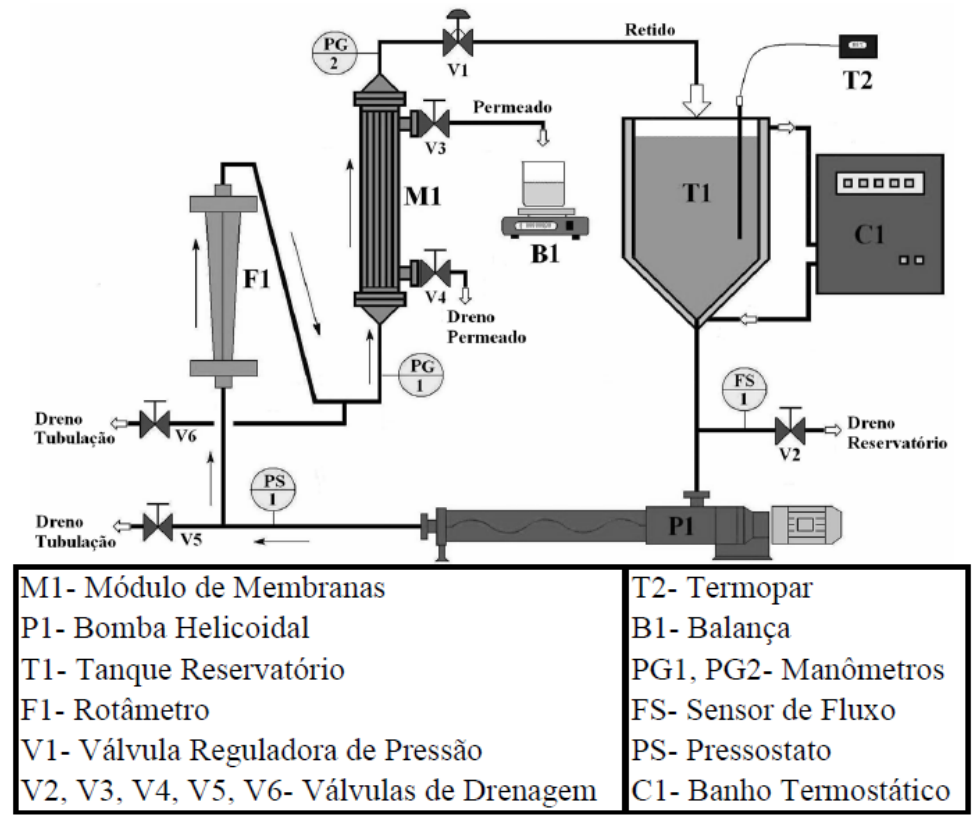

O sistema de alimentação do módulo experimental é composto por um reservatório com capacidade de 5 litros, em aço inoxidável, com camisa dupla e uma bomba de deslocamento positivo com inversor de frequência, que permite a operação em diferentes vazões, ou seja, possibilita variar a velocidade tangencial de filtração. A instrumentação é composta de dois indicadores de pressão (manômetros) e um rotâmetro para indicação de vazão da bomba de alimentação. Os dispositivos de segurança presentes na unidade são um pressostato, que limita a pressão de operação da bomba, e um dispositivo contra trabalho a seco da bomba. As membranas utilizadas são instaladas em um módulo de aço inoxidável, fixado à tubulação por meio de flanges.

Para a purificação da mistura, as mesmas foram mantidas à temperatura de $60^{\circ} \mathrm{C}$ no tanque de alimentação e então bombeadas para a membrana. A pressão foi ajustada por meio de uma válvula manual e a temperatura controlada com um banho termostático. O permeado foi coletado e o concentrado totalmente recirculado para o tanque de alimentação.

O fluxo permeado foi obtido por meio da determinação da massa de permeado coletada em função do tempo, medida em uma balança semi-analítica (BG 4000-Gehaka), e calculado de acordo com a equação.

$$
J_{p e r m}=\frac{m_{p}}{A \cdot t}
$$

A: área de permeação da membrana em $\mathrm{m}^{2}$.

$t$ : intervalo de tempo em horas;

$J_{\text {perm: }}$ : fluxo permeado $\left(\mathrm{kg} / \mathrm{h} . \mathrm{m}^{2}\right)$

$m_{p}$ : massa de permeado em $\mathrm{kg}$ 
Foram feitas duas misturas com diferentes composições, os componentes forem pesados e misturados totalizando uma mistura entre 3 e 4 litros. Essas misturas foram feitas para simular as impurezas presentes na glicerina como coproduto do processo de produção industrial do biodiesel. A Tabela 1 apresenta as composições utilizada neste trabalho.

Tabela 1 - Composições das misturas

\begin{tabular}{|c|c|c|}
\hline Compostos & Mistura 1 & Mistura 2 \\
\hline \hline Glicerina Bruta & $70 \%$ & $70 \%$ \\
\hline Água acidificada $\left(0,5 \% \mathrm{H}_{3} \mathrm{PO}_{4}\right)$ & $10 \%$ & $10 \%$ \\
\hline Etanol & $10 \%$ & $1 \%$ \\
\hline Biodiesel & $10 \%$ & $19 \%$ \\
\hline
\end{tabular}

Todos os experimentos foram realizados em uma vazão de $700 \mathrm{~L} / \mathrm{h}$, o que corresponde a uma velocidade tangencial de aproximadamente $8 \mathrm{~m} / \mathrm{s}$.

A média de todos os fluxos é denominada de fluxo médio. Além do fluxo médio foi calculado o fluxo estabilizado por meio da média dos últimos 10 valores de fluxo.

Após cada processamento, a unidade experimental foi imediatamente limpa a fim de preservar todos os equipamentos e restaurar a permeabilidade da membrana utilizada. A limpeza do módulo foi feita com múltiplas lavagens com água, sabão, solução de $\mathrm{NaOH} 2 \%$ e por fim água deionizada. A membrana foi limpa com lavagens intercaladas de solução a quente de $\mathrm{NaOH} 2 \%$ e $\mathrm{HCl} 2 \%$.

\section{RESULTADOS E DISCUSSÃO}

$\mathrm{Na}$ Figura 2, são apresentados os fluxos de permeado das misturas 1 e 2 descritas na Tabela 1, utilizando a membrana de 5kDa e pressão de 3 bar.

Figura 2 - Gráficos dos fluxos das misturas 1 e 2, respectivamente
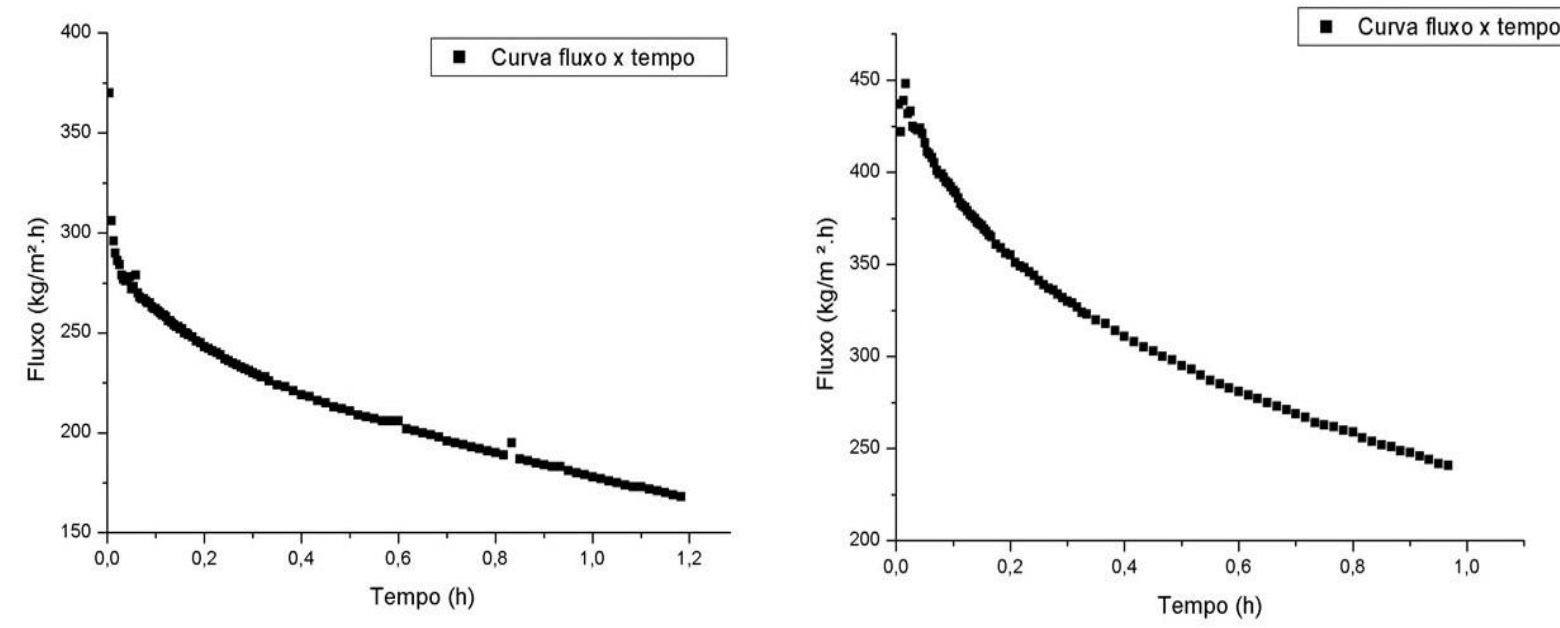
A mistura 1 apresentou fluxo médio de $266,23 \mathrm{~kg} / \mathrm{m}^{2}$.h e fluxo estabilizado de 198,50 $\mathrm{kg} / \mathrm{m}^{2} . \mathrm{h}$, diferente da mistura 2, que teve um fluxo médio de $339,50 \mathrm{~kg} / \mathrm{m}^{2} . \mathrm{h}$ e fluxo estabilizado de $284,30 \mathrm{~kg} / \mathrm{m}^{2} . \mathrm{h}$.

Com as diferentes composições, é possível comparar a influência do aumento de percentual do biodiesel e diminuição do percentual de etanol presente na mistura. $\mathrm{O}$ etanol, considerado um cossolvente, faz com que a glicerina seja dissolvida no biodiesel, e assim, quanto menor o percentual de etanol a mistura, maior será o fluxo de permeado. Isso é justificado pelo fato de que quando o biodiesel não está dissolvido na glicerina, o fluxo é facilitado por causa da presença de partículas menores. Como na mistura 2 o percentual de biodiesel é maior e do etanol é menor que a mistura 1, os fluxos médio e estabilizado foram maiores do que na mistura 1. Entretanto, na presença de um maior percentual de biodiesel, e, portanto, maior quantidade de impurezas, a queda do fluxo se iniciou mais rapidamente, ou seja, o efeito fouling foi mais evidente na mistura 2 pois teve um acréscimo de biodiesel comparado à mistura anterior. Isso caracteriza maior quantidade de impurezas justificando a queda abrupta do fluxo.

No decorrer do tempo, o acúmulo de resíduos na membrana, também conhecido como fouling, faz com que haja uma queda do fluxo da purificação, fazendo com que o fluxo estabilizado seja menor que o médio em ambas as misturas. Esse processo de incrustação acontece devido às impurezas, presentes na glicerina bruta e biodiesel, obstruírem os poros da membrana causando uma diminuição da área de permeação e com isso redução do fluxo de permeado com o passar do tempo.

\section{CONCLUSÃO}

Nas condições em que os ensaios foram conduzidos pode-se concluir que:

A mistura 2, que possui uma maior porcentagem de biodiesel, apresentou um fluxo de permeado maior devido à diminuição do tamanho das partículas. Por outro lado, a grande quantidade de impurezas que essa mistura apresenta ocasionou um menor tempo na ultrafiltração pelo fato dos poros da membrana sofrerem entupimento mais rapidamente.

\section{REFERÊNCIAS}

ARDI, M. S.; AROUA, M. K.; AWANIS HASHIM, N. Progress, prospect and challenges in glycerol purification process: A review. Renewable and Sustainable Energy Reviews, v. 42, p. 1164-1173, 2015.

GOMES, M. C. S. Estudo da produção de biodiesel por transesterificação etílica e sua purificação utilizando processos com membranas. Maringá: UEM, 2012. Tese (Doutorado em Engenharia Química) - Universidade Estadual de Maringá, 2012.

GOMES, M. C. S.; ARROYO, P. A.; PEREIRA, N. C. Biodiesel production from degummed soybean oil and glycerol removal using ceramic membrane. Journal of Membrane Science, v. 378, p. 453-461, 2011.

GERIS, R.; SANTOS, N. A. C.; AMARAL, B. A.; MAIA, I. S.; CASTRO, V. D.; CARVALHO, J. R. M. Biodiesel de Soja - Reação de Transesterificação para Aulas Práticas de Química Orgânica. Química Nova, 30 (5) p.1369-1373, 2007. 
HABERT, A. C.; BORGES, C. P.; NÓBREGA, R. Processos de Separação por Membranas. Rio de Janeiro: E-papers, 2006.

HUNSOM, M; AUTTHANIT, C. Adsorptive purification of crude glycerol by sewage sludge-derived activated carbon prepared by chemical activation with $\mathrm{H}_{3} \mathrm{PO}_{4}, \mathrm{~K}_{2} \mathrm{CO}_{3}$ and KOH. Chem Eng. v. 43, p. 229:334, 2013.

MOTA, C. J. A.; SILVA, C. X. A.; GONÇALVES, V. L. C. Gliceroquímica: novos produtos e processos a partir da glicerina de produção de biodiesel. Química Nova, v. 32, p. 639648, 2009.

QUISPE, C. A. G.; CORONADO, C. J. R.; CARVALHO JR, J. A. Glycerol: Production, consumption, prices, characterization and new trends in combustion. Renewable and Sustainable Energy Reviews, v. 27, p. 475-493, 2013.

TAN, H. W.; ABDUL AZIZ, A. R.; AROUA, M. K. Glycerol production and its applications as a raw material: A review. Renewable and Sustainable Energy Reviews, v. 27, p. 118$127,2013$. 